\title{
Luteal-phase defect induced by deprivation of FSH at a specific period of the follicular phase prevents pregnancy in the bonnet monkey (Macaca radiata)*
}

\author{
N. Ravindranath and N. R. Moudgal \\ Primate Research Laboratory and Centre for Advanced Research in Reproductive Biology, \\ Department of Biochemistry, Indian Institute of Science, Bangalore 560012 , India
}

\begin{abstract}
Summary. Female bonnet monkeys were injected i.v. with $25 \mu$ l antiserum to FSH on Days 5, 6 or 7 of the cycle: the length of the luteal phase was shortened but there was no alteration in cycle length. Proven fertile females $(\mathrm{N}=6)$ were caged throughout the period of the experiment ( 6 cycles) with proven fertile males and treated with $25 \mu \mathrm{l}$ FSH antiserum on Day 7 of each of 3 successive cycles. Out of 18 cycle exposures during the treatment phase, 17 were ovulatory, but no pregnancies occurred. In the posttreatment phase, 5 monkeys became pregnant within 3 cycle exposures. These results show that it is possible to render female monkeys infertile by creating luteal insufficiency and this can be achieved repeatedly in a reproducible manner by depriving the cyclic females of FSH support on Day 7 of consecutive cycles.
\end{abstract}

Keywords: monkey; ovary; follicular phase; luteal phase defect; pregnancy

\section{Introduction}

The luteal phase of the menstrual cycle in the non-human primate extends from 12 to 16 days (calculated from the day of ovulation) depending on the species (Moudgal, 1984). The role of pituitary LH in the support and maintenance of luteal function both during the cycle and early pregnancy is well established (Moudgal, 1975; Moudgal et al., 1972, 1978; Mukku \& Moudgal, 1979). Luteal tissue does not have receptors for FSH (Sheela Rani \& Moudgal, 1983) and a lack of FSH during the luteal phase does not affect luteal function (Ravindranath, 1988). However, it has been suggested that a reduction in FSH concentrations during the early follicular phase with crude inhibin could influence luteal function, resulting in luteal phase defects (Stouffer \& Hodgen, 1980; diZerega \& Hodgen, 1981; Jayaraman et al., 1986). Minakami et al. (1985) have attempted to correlate luteal phase defects with low serum FSH, LH and prolactin values in women and Wilks $e t$ al. (1976) observed that inappropriate FSH:LH ratios are responsible for short luteal phases seen in monkeys. Thau et al. (1979) reported that adult cyclic rhesus monkeys actively immunized against the $\beta$ subunit of ovine LH show normal follicular maturation, ovulation and corpus luteum formation but exhibit a luteal defect in that the corpus luteum is unable to support the establishment of pregnancy. However, these monkeys had higher than normal concentrations of serum FSH.

In the current study, using a specific FSH antiserum we have investigated the possible effect of neutralization of FSH during midfollicular phase on luteal function.

*Reprint requests to: Professor N. R. Moudgal. 


\section{Materials and Methods}

Experimental animals. Healthy adult female bonnet monkeys of proven fertility weighing between 5 and $6 \mathrm{~kg}$ were used. Before the start of the study, these monkeys had at least 2 consecutive ovulatory menstrual cycles of normal duration (28-30 days). Details regarding the husbandry of these monkeys have been described elsewhere (Ravindranath \& Moudgal, 1987). For the pregnancy establishment studies, the females were kept individually with proven fertile males throughout the study period.

Antiserum to oFSH. Details regarding the production and characterization of the antiserum for efficacy, specificity and cross-reactivity are provided by Ravindranath et al. (1989).

Briefly, the antiserum to ovine FSH, raised in a male bonnet monkey, exhibited no cross-reactivity with primate LH (hLH used as a standard) after treatment with an ovine LH affinity matrix according to procedure developed by Murthy \& Moudgal (1987). The purified antiserum was able to bind ovine FSH, human FSH and monkey FSH. The binding affinity for hFSH determined using Scatchard analysis was $0.3 \times 10^{10} \mathrm{M}^{-1}$. The hFSH bioneutralizing capacity of the antiserum, tested using an in-vitro rat granulosa cell system, was $8 \mu \mathrm{g} \mathrm{hFH} / \mathrm{ml}$.

Hormone assays. Serum oestradiol and progesterone concentrations were estimated by specific radioimmunoassays, details of which have been provided elsewhere (Ravindranath \& Moudgal, 1987). The assays were run using serum samples separated from blood withdrawn by femoral venepuncture in unanaesthetized monkeys. The oestradiol antiserum used in the assay cross-reacted with oestrone $(10 \%)$ and oestriol $(1 \%)$. The inter- and intra-assay coefficients of variation were 15 and $12 \cdot 5 \%$ respectively. The progesterone antiserum cross-reacted with $17 \alpha$-hydroxyprogesterone $(3 \%)$ and $20 \alpha$-dihydroprogesterone $(5 \%)$. The inter- and intra-assay coefficients of variations were $9 \%$ and $8 \%$ respectively. The sensitivity of the assay for progesterone was $0.01 \mathrm{ng}$ and for oestradiol $0.02 \mathrm{ng}$.

The radioimmunoassay used for determining chorionic gonadotrophin (CG) for diagnosis of pregnancy was according to the method described by Jagannadha Rao et al. (1984). This consisted of incubating serum samples and hCG standards (ranging from $100 \mathrm{pg}$ to $100 \mathrm{ng}$ ) and ${ }^{125} \mathrm{I}$-labelled hCG with a rabbit antiserum to the $\beta$-subunit of ovine $\mathrm{LH}$ for $12 \mathrm{~h}$ at room temperature. Bound and free hormones were separated using goat anti-rabbit $\gamma$-globulin serum and the radioactivity precipitated was measured in an auto-gamma spectrometer. The monkey CG in serum samples was expressed as hCG equivalents read from hCG standards used in the assay. The assay had an intra-assay coefficient of variation of $10.8 \%$ and a sensitivity of $5 \mathrm{ng} / \mathrm{ml}$. The assay is specific to CG and does not exhibit cross-reactivity with monkey pituitary extract or serum from a castrated monkey.

Fertility tests. Fertility testing of females is normally undertaken in our colony by exposing proven fertile cyclic females between Days 9 and 14 of the cycle (periovulatory period) to proven fertile males. In the present investigation, however, each female was kept with a single male for the entire duration of the study as we expected the treatment given to alter the ovulatory period.

Indicators used to confirm pregnancy. Earlier studies from this laboratory have shown that in the mated female bonnet monkey high serum progesterone and oestrogen concentrations beyond Day 25 of the cycle (Prahalada $e t$ al., 1975; Ravindranath \& Moudgal, 1987) and increasing concentrations of serum CG between Days 28 and 35 of the cycle (Jagannadha Rao et al., 1984) are positive indicators of the occurrence of conception. If necessary, pregnancy was also confirmed by rectal palpation after Day 45 from the last menstrual flow.

Statistical analysis. The data were statistically analysed by using Student's $t$ test and by $\chi^{2}$ analysis.

\section{Results}

\section{Effect of FSH antiserum injection during the follicular phase on luteal function of cyclic monkeys}

Based on earlier studies (Ravindranath et al., 1989), groups of monkeys received $25 \mu \mathrm{FSH}$ antiserum/monkey on Day 5, 6 or 7 of the cycle. Although antiserum injection on any of the 3 days had no effect on the overall length of the cycle, the luteal phase was progressively shortened depending on the day of treatment, (Table 1). The total progesterone produced during the luteal phase, however, was reduced only by $20 \%$ when antiserum was injected on Day 7 ; injections on Days 6 or 5 had no effect (Table 1).

When antiserum to FSH was injected on Day 7 of each of 3 consecutive cycles, the length of the luteal phase was consistently shortened by $40 \%$ and total progesterone produced during the luteal phase by $24-31 \%$ in each of the treatment cycles (Table 2). Serum oestrogen concentrations on Days 9 and 16 were also similar in each of the 3 cycles (Table 2). The oestrogen and progesterone concentrations in a typical treatment cycle are shown in Fig. 1. While the time taken for serum 
Table 1. Effect of FSH antiserum injection during the mid-follicular phase on the length of the luteal phase in bonnet monkeys

\begin{tabular}{lccccc}
\hline Group & $\begin{array}{c}\text { No. of } \\
\text { monkeys }\end{array}$ & $\begin{array}{c}\text { Day of } \\
\text { injection }\end{array}$ & $\begin{array}{c}\text { Length of luteal } \\
\text { phase (days) } \\
\text { (\% reduction } \\
\text { over control) }\end{array}$ & $\begin{array}{c}\text { Progesterone } \\
\text { produced during } \\
\text { luteal phase } \\
\left(\mathrm{cm}^{2}\right)^{*}\end{array}$ & $\begin{array}{c}\text { Length of } \\
\text { cycle } \\
\text { (days) }\end{array}$ \\
\hline I & 3 & - & $18 \cdot 2 \pm 1 \cdot 5$ & $49 \cdot 0 \pm 3 \cdot 3$ & $27 \cdot 3 \pm 1 \cdot 2$ \\
II & 4 & 5 & $15 \cdot 0 \pm 0 \cdot 8(18)$ & $51 \cdot 3 \pm 2 \cdot 5$ & $27 \cdot 0 \pm 1 \cdot 4$ \\
III & 3 & 6 & $14 \cdot 0 \pm 1 \cdot 3^{*}(20)$ & $47 \cdot 6 \pm 1 \cdot 5$ & $27 \cdot 3 \pm 2 \cdot 3$ \\
IV & 9 & 7 & $10 \cdot 8 \pm 1 \cdot 9^{* *}(41)$ & $40 \cdot 7 \pm 2 \cdot 1$ & $26 \cdot 7 \pm 2 \cdot 2$ \\
\hline
\end{tabular}

Values are as mean \pm s.d.

$\uparrow$ Time elapsed between day of oestrogen surge and onset of next menses.

$\ddagger$ Computed from the area under the curve of progesterone secretion from the day of oestrogen surge to onset of next menses.

$*^{*}<0.05$ compared with Group I.

${ }^{* *} P<0.01$ compared with Group I.

progesterone values to reach a peak (ascending phase) in the normal and treatment cycle were similar ( 10 and 8 days from the oestrogen surge) there was a marked difference in the time taken for the progesterone concentrations to fall from the peak to basal levels signalling the end of the cycle ( 8 and 4 days).

Table 2. Effect of FSH antiserum injection on Day 7 of each of 3 consecutive cycles

\begin{tabular}{|c|c|c|c|c|}
\hline & \multirow{2}{*}{$\begin{array}{l}\text { Control } \\
\text { cycle }\end{array}$} & \multicolumn{3}{|c|}{ Treatment cycles } \\
\hline & & I & II & III \\
\hline \multicolumn{5}{|l|}{ Oestradiol conc. (pg/ml) } \\
\hline Day 7 & $340 \pm 48$ & $330 \pm 128$ & $386 \pm 186$ & $360 \pm 130$ \\
\hline Day 9 & $512 \pm 288$ & $130 \pm 53^{*}$ & $130 \pm 98^{*}$ & $100 \pm 54^{*}$ \\
\hline Day 16 & $200 \pm 40$ & $528 \pm 240^{*}$ & $436 \pm 172^{*}$ & $428 \pm 104^{*}$ \\
\hline \multicolumn{5}{|l|}{$\begin{array}{l}\text { Progesterone conc. during } \\
\text { entire luteal phase (area }\end{array}$} \\
\hline under the curve, $\mathrm{cm}^{2}$ ) & $52 \cdot 0 \pm 3 \cdot 6$ & $38 \cdot 7 \pm 3 \cdot 1^{*}$ & $40 \cdot 2 \pm 2 \cdot 8^{*}$ & $36 \cdot 9 \pm 3 \cdot 4^{*}$ \\
\hline Length of luteal phase (days) & $18 \cdot 2 \pm 1 \cdot 5$ & $10 \cdot 6 \pm 2 \cdot 4^{*}$ & $11 \cdot 0 \pm 2 \cdot 4^{*}$ & $10.8 \pm 1.9 *$ \\
\hline Length of cycle (days) & $27 \cdot 3 \pm 1 \cdot 2$ & $26.5 \pm 1.8$ & $25 \cdot 6 \pm 3 \cdot 4$ & $26 \cdot 7 \pm 2 \cdot 2$ \\
\hline
\end{tabular}

Values are mean \pm s.d. for 6 monkeys.

*Significantly different from corresponding control values, $P<0.05$.

\section{Effect of FSH antiserum on Day 7 of the cycle on establishment of pregnancy}

Proven fertile monkeys $(\mathrm{N}=6)$ with regular cycles were treated with $25 \mu$ FSH antiserum on Day 7 of each of 3 consecutive cycles. The females were caged individually with proven fertile males for the duration of the study which extended over 6 cycles. Except for one cycle, all the treatment cycles $(17 / 18)$ were ovulatory as judged by serum oestrogen and progesterone profiles. No pregnancies were recorded during the treatment period of 3 consecutive cycles (Table 3 ). According to colony norms determined over the past 5 years, $82 \%$ of proven fertile cyclic bonnet monkeys should have become pregnant within 3 cycle exposures, each cycle exposure covering a 6-day period from Days 9 to 14 of cycles (Ravindranath \& Moudgal, 1987). When antiserum treatment was stopped, 5 of the monkeys $(83 \%)$ became pregnant within the next 3 cycle exposures (Table 3 ) $\left(P<0.01, \chi^{2}\right)$. In this study, the experimental monkeys served as their own controls during the post-treatment period. The current results also show that the percentage conception recorded in the colony after 3 cycle exposures, each from Days 9 to 14 of the cycle, does not change even when the females are kept with males for the entire duration of 3 cycles in the post-treatment period. 


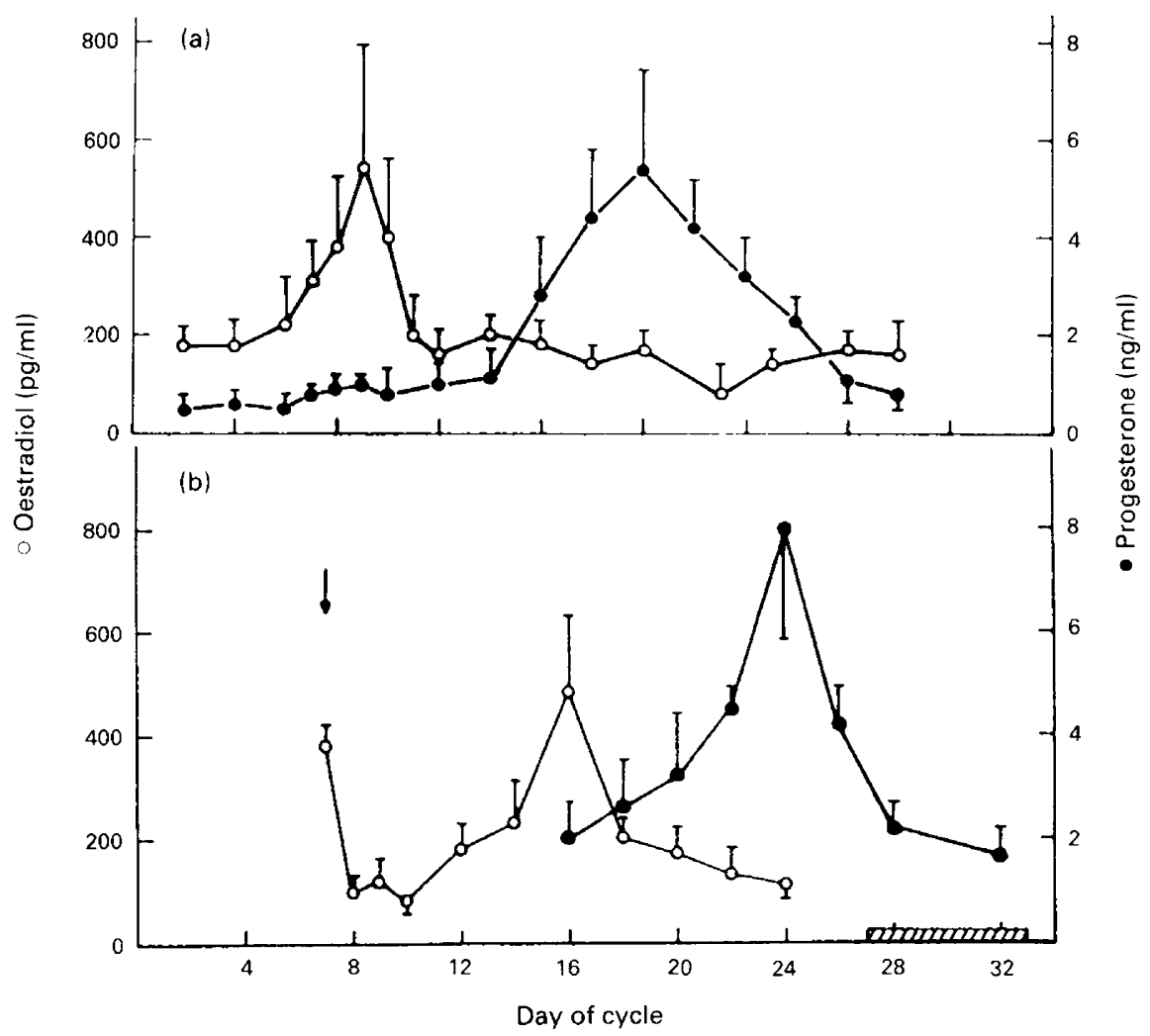

Fig. 1. Serum oestrogen and progesterone concentrations in female bonnet monkeys during (a) a control cycle and (b) a cycle in which $25 \mu \mathrm{FSH}$ antiserum were given i.v. on Day 7 of the cycle (arrow). Values are mean \pm s.d. for (a) 3 and (b) 6 monkeys.

\section{Discussion}

The primary objective of this study was to ascertain whether luteal dysfunction could be consistently achieved in adult female monkeys by manipulating FSH concentrations during the mid-follicular phase. The results provide unequivocal evidence for the occurrence of such an event. Our earlier study (Ravindranath et al., 1989) showed that the ovarian follicle on Day 7 of the cycle is most sensitive to FSH deprivation and that the maturing follicle(s) succumbs to such hormonal lack. A new follicle/corpus luteum that takes the place of the defunct dominant follicle appears from the current study to be also defective. However, injection of the minimal essential dose of FSH antiserum had no effect on overall cycle length, despite ovulation and luteal function being attributed to a second follicle that matures to a dominant state 9 days after the demise of the first follicle. Luteal dysfunction can be related to (a) the total progesterone produced during the luteal phase being reduced, (b) the period over which progesterone produced being significantly lessened, or (c) the corpus luteum being incapable of being 'rescued' from cyclic demise by exogenous or endogenous chorionic gonadotrophin produced after the establishment of pregnancy. While we have shown here by direct measurement that possibilities (a) and (b) have been affected significantly, possibility (c) has also been shown by fertility testing to be affected.

Our earlier results, obtained from in-vivo and in-vitro studies, showed that the corpus luteum of the bonnet monkey can be rescued up to Day 27 of the cycle (Mukku \& Moudgal, 1979). Bonnet 
Table 3. Effect of FSH antiserum treatment on Day 7 of each of 3 successive cycles and withdrawal on fertility status of bonnet monkeys

\begin{tabular}{|c|c|c|c|c|c|c|}
\hline \multirow[b]{3}{*}{ Monkey } & \multicolumn{6}{|c|}{ Pregnancy establishment $\dagger$} \\
\hline & \multicolumn{3}{|c|}{$\begin{array}{l}\text { Treatment } \\
\text { cycles }\end{array}$} & \multicolumn{3}{|c|}{$\begin{array}{c}\text { Post-treatment } \\
\text { cycles }\end{array}$} \\
\hline & I & II & III & I & II & III \\
\hline 38 & - & - & - & + & & \\
\hline 32 & - & - & - & - & - & - \\
\hline 174 & - & - & - & - & - & + \\
\hline 130 & - & - & - & - & + & \\
\hline 4 & - & - & - & + & & \\
\hline 168 & - & - & - & + & & \\
\hline
\end{tabular}

+Verified by serum oestrogen, progesterone and $\mathrm{CG}$ concentrations from Day 25 onwards and by rectal palpation, if needed, after Day 45.

$\ddagger$ Out of 18 treatment cycles, 17 were ovulatory as judged by oestrogen/progesterone profiles.

monkeys which have undergone a fertile mating, however, exhibit serum progesterone concentrations markedly higher during the peri-implantation period (i.e. between Days 18 and 23 of the cycle or 7-9 days after fertilization) compared to the equivalent period of the cycle in unmated monkeys (Mukku \& Moudgal, 1979), indicating that the luteal tissue of mated monkeys could be receiving a 'rescue signal' in the form of a luteotrophic stimulus before implantation. This is in keeping with the observation that blastocysts of the rabbit (Saxena et al., 1974) and the human (Fishel et al., 1984) are capable, even before implantation, of secreting CG-like substances which have luteotrophic activity. In the current study, although proven fertile monkeys were used no pregnancies were recorded during the treatment phase of 17 ovulatory mated cycles and the progesterone profile did not show the occurrence of luteal rescue. The significance and specificity of the antiserum effect was shown when during the subsequent 3 ovulatory cycle exposures no antiserum was given and 5 out of 6 monkeys became pregnant. The above results suggest that pregnancy establishment is blocked in treatment cycles, perhaps due to the inability of the corpus luteum to be rescued by any CG produced by the blastocyst. Stouffer \& Hodgen (1980) have observed that the corpus luteum of cyclic but unmated monkeys treated with pig follicular fluid during the early follicular phase does not respond to exogenous hCG injection. Although the mechanism by which FSH deprivation during the follicular phase causes luteal dysfunction remains to be investigated at the cellular and molecular level, this study shows the possibility of using inhibin-like peptides during the mid-follicular phase to achieve contraception in the female. In a preliminary study, we have observed that administration of pig follicular fluid on Days 6 and 7 of the cycle to bonnet monkeys leads to a marked $(\sim 45 \%)$ reduction in luteal progesterone output (Moudgal et al., 1987).

Besides the luteal defect per se, there may be another reason why pregnancy could not be established in the antiserum-treated monkeys. Normally, the corpus luteum of the monkey is functional for 14-16 days from the day of ovulation. In the FSH antiserum-treated monkeys ovulation was delayed by 6 days because of the time taken for the appearance of a new follicle following the demise of the first dominant follicle around Day 8 of the cycle. This delay and fall in oestrogen secretion probably caused changes in the transformation of secretory endometrium necessary for receiving the embryo. Balasch (1987) has observed that in infertile women the mid-luteal plasma progesterone value alone cannot be taken as an index of adequate transformation of the endometrium. Corpus luteum dysfunction and infertility in primates has been described as a sequel to 
abnormal folliculogenesis (diZerega \& Hodgen, 1981). Balasch et al. (1986) further report that delayed ovulation occurring during a menstrual cycle of normal length may in itself be the cause of infertility, since luteal insufficiency in women having a long follicular phase has been reported.

Aided by grants from the Indian Council of Medical Research, New Delhi. We thank Mr V. Ramesh, Mrs N. S. Srilatha and Mr B. Shanmughavelu for skilled technical assistance.

\section{References}

Balasch, J., Creus, M., Marquez, M., Burzaco, I. \& Vanrell, J.A. (1986) The significance of luteal phase deficiency on fertility: a diagnostic and therapeutic approach. Human Reprod. 1, 145-147.

Balasch, J. (1987) Luteal phase insufficiency: clinical aspects. J. Steroid Biochem. 27, 393-397.

diZerega, G.S. \& Hodgen, G.D. (1981) Folliculogenesis in the primate ovarian cycle. Endocrine Rev. 2, $27-49$.

Fishel, S.B., Edwards, R.G. \& Evans, C.J. (1984) Human chorionic gonadotropin secreted by preimplantation embryos cultured in vitro. Science, $N Y 223,816-818$.

Jagannadha Rao, A., Kotagi, S.G. \& Moudgal, N.R. (1984) Serum concentrations of chorionic gonadotropin, oestradiol- $17 \boldsymbol{\beta}$ and progesterone during early pregnancy in the south Indian bonnet monkey (Macaca radiata). J. Reprod. Fert. 70, 449455.

Jayaraman, S., Krishnan, K.A., Vanage, G.R. \& Sheth, A.R. (1986) Interference in primate follicular maturation: an approach with inhibin for female contraception. $A d v$. Contraception 2, 337-342.

Minakami, H., Kimura, K. \& Tamada, T. (1985) Low serum levels of FSH, LH and Prolactin in luteal phase inadequacy. Endocr. japan. 32, 265-270.

Moudgal, N.R. (1975) Passive immunization with gonadotropin antisera as a method of menstrual regulation in the primate. In Immunization with Hormones in Reproduction Research, pp. 233-237. Ed. E. Nieschlag. North Holland, Amsterdam.

Moudgal, N.R. (1984) Corpus luteum of the nonhuman primate. In Advances in Veterinary Science and Comparative Medicine: Research on Nonhuman Primate, pp. 343-362. Eds C. E. Cornelius, C. F. Simpson \& A. G. Hendrickx. Academic Press, New York.

Moudgal, N.R., MacDonald, G.J. \& Greep, R.O. (1972) Role of endogenous primate $\mathrm{LH}$ in maintaining corpus luteum of the monkey. J. clin. Endocr. Metab. 35, $113-116$.

Moudgal, N.R., Mukku, V.R., Prahalada, S., Murty, G.S.R.C. \& Li, C.H. (1978) Passive immunization with an antibody to the $\beta$-subunit of ovine luteinizing hormone as a method of early abortion-a feasibility study in monkeys (Macaca radiata). Fert. Steril. 30, 223-229.

Moudgal, N.R., Dighe, R.R., Srinath, B.R., Ravindranath, N. \& Kurkalli, B.S. (1987) Assessment of contraceptive potential of inhibin using nonhuman primate models. In Inhibin-Non-Steroidal Regulation of Follicle Stimulating Hormone Secretion, pp. 289-298. Eds H. G. Burger, D. M. de Kretser, J. K. Finlay \& M. Igarashi. Raven Press, New York.
Mukku, V.R. \& Moudgal, N.R. (1979) Regulation of corpus luteum function in the subhuman primate-a study in bonnet monkeys. In Recent Advances in Reproduction and Regulation of Fertility, pp. 135142. Ed. G. P. Talwar. Elsevier/North Holland, Amsterdam.

Murthy, G.S. \& Moudgal, N.R. (1987) Immunological cross reactivity of antisera to purified hormones. $J$. Biosci. 12, 23-31.

Prahalada, S., Mukku, V.R., Jagannadha Rao, A. \& Moudgal, N.R. (1975) Termination of pregnancy in macaques (Macaca radiata) using monkey antiserum to ovine luteinizing hormone. Contraception 12, 137-147.

Ravindranath, N. (1988) Studies on the reproductive endocrinology of the female bonnet monkey (Macaca radiata): hormonal regulation of follicular maturation, luteal function and implantation. Ph.D. thesis, Indian Institute of Science, Bangalore.

Ravindranath, N. \& Moudgal, N.R. (1987) Use of tamoxifen, an antioestrogen, in establishing a need for oestrogen in early pregnancy in the bonnet monkey (Macaca radiata). J. Reprod. Fert. 81, $327-336$.

Ravindranath, N., Sheela Rani, C. S., Martin, F. \& Moudgal, N.R. (1989) Effect of FSH deprivation at specific times on follicular maturation in the bonnet monkey (Macaca radiata). J. Reprod. Fert. 87, $231-241$.

Saxena, B.B., Hasan, S.H., Haour, F. \& SchmidtGollwitzer, M. (1974) Radioreceptor assay of human chorionic gonadotropin: Detection of early pregnancy. Science, NY 184, 793-795.

Sheela Rani, C.S. \& Moudgal, N.R. (1983) Advances in immunobiology of gonadotropins. In Hormonal Proteins and Peptides, pp. 135-184. Ed. C. H. Li. Academic Press, New York

Stouffer, R.L. \& Hodgen, G.D. (1980) Induction of Luteal phase defects in rhesus monkeys by follicular fluid administration at the onset of the menstrual cycle. J. ctin. Endocr. Metab. 51, 669-671.

Thau, R.B., Sundaram, K., Thornton, Y.S. \& Seidman, L.S. (1979) Effects of immunization with the subunit of ovine luteinizing hormone on corpus luteum function in the rhesus monkey. Fert. Steril. 31, 200-204.

Wilks, J.W., Hodgen, G.D. \& Ross, G.T. (1976) Luteal phase defects in the rhesus monkey: the significance of serum FSH:LH ratios. J. clin. Endocr. Metab. 43, 1261-1267. 